\title{
Review on Research and Developments of Bicycle Brake Calipers using Natural Fiber
}

\author{
Theebbanraj Asokan ${ }^{1}$ \\ Umar Nirmal ${ }^{*}$ \\ Saijod T. W. Lau ${ }^{3}$
}

${ }^{1}$ Researcher, Centre of Advanced Mechanical and Green Technology, Faculty of Engineering and Technology, ${ }^{2 *}$ Senior Lecturer, Centre of Advanced Mechanical and Green Technology Faculty of Engineering and Technology, Multimedia University, Malaysia ${ }^{3}$ Lecturer, Faculty of Engineering and Technology, Multimedia University, Malaysia (nirmal@mmu.edu.my)*

This journal is licensed under a Creative Commons Attribution-NonCommercial 4.0 International License (CC-BY-NC). Articles can be read and shared for noncommercial purposes under the following conditions:

- BY: Attribution must be given to the original source (Attribution)

- NC: Works may not be used for commercial purposes (Noncommercial)

This license lets others remix, tweak, and build upon your work non-commercially, and although their new works must also acknowledge you and be non-commercial, they don't have to license their derivative works on the same terms. License Deed Link: http://creativecommons.org/licenses/by-nc/4.0/ Legal Code Link: http://creativecommons.org/licenses/by-nc/4.0/legalcode $A B C$ Research Alert uses the CC BY-NC to protect the author's work from misuse.

\section{Abstract}

The current review focuses on the development of the bicycle brake system from the 1800still year 2017. Based on this review, it was found that the bicycle went through major design evolution up until 'safety bicycles' were created. Then, bicycles were upgraded according to specialized aspects such as braking system, comfort, gear system, tangent stokes and other aspects. Within the aspect of bicycle braking system, the designs were more diversified and can be categorized into three categories known as tire brakes, rim brakes and brakes in or attached to the hub. Once a certain design has reached its utmost aerodynamic capabilities, it will usually be upgraded through means of material composition. A review on natural fiber composites was also done as to see its capabilities of replacing synthetic composites. Based on this review, it was found that due to the natural fiber composite's lightweight and favorable mechanical properties, it is very possible to realizing the idea of replacing the synthetic composites used in a bicycle braking system with natural fiber composite. This paper also proposes future research path ways to further enhance the bicycle as a whole through comprehensive research, trial and error.

\section{Keywords}

Bicycle;history; bicycle brake; polymers; natural fiber composites. 


\section{Introduction}

In this modern era, the technological advances that uses petrochemical resources has grown by leaps and bounds bringing about incredible benefits to mankind. However, these advances would be increasingly unsustainable over time due to the strain it places on the current resources [1]. The urge to develop materials using renewable resources to counter the environmental threat and to the uncertainty of petroleum supply is increasing among worldwide researches [2].

Natural fiber in particular have been researched and developed significantly over the past few years due to their low density, biodegradable, non-abrasive and highly specific properties [3]. Also, as natural fiber has decent price stability as well as being independent to oil prices, their specific properties are researched thoroughly to replace many petroleum based products.

Moreover, since 1980s until today, bicycles have been and are employed for many uses such as for transportation, recreation, tourism, fitness, and leisure. The existence of bicycle racing instead puts the speed, design, durability, braking capabilities and many other aspects of the bicycle itself to be thoroughly researched [4]. The bicycle brake design and material used plays a very crucial role in the efficacy of bicycles.

In regards to this, this current study aims to make use of the speciality of a natural fiber composite and research its capabilities as well as its effectiveness in order to replace a petroleum based bicycle brake calliper. The entire research consist of four main parts; preparing and treating the natural fiber, designing and fabrication of the bicycle brake calliper, testing and collecting results, and finally preparing the report.

\subsection{History}

\section{a) Draisine (1817 - 1819)}

The origin of bicycle dates far back to the year 1817, when Karl Friedrich Christian Ludwig FreiherrDrais von Sauerbronn, also known as Baron Karl Drais at the time had an intention of reducing four-wheeled vehicles to two wheelers [4]. He was known as one the most creative German inventors of the 19th century. He created the laufmaschine which means running machine but usually known as Draisine as shown in Figure 1. The design was primitive as it is propelled by the rider pushing the ground using both their feet, however it is the first two wheeled vehicle with both wheels in line to ever be created [5]. The frame and wheels were made of wood. A leather saddle were nailed to the frame for the riders to sit. Figure 2 shows a more detailed isometric drawing of the draisine. The running machine was named Draisine in Germany however it became known under various names in other countries such as 'velocipede' (fast feet) or 'Draisienne' in France as well as 'hobby horse' or 'dandy horse' in England [6].

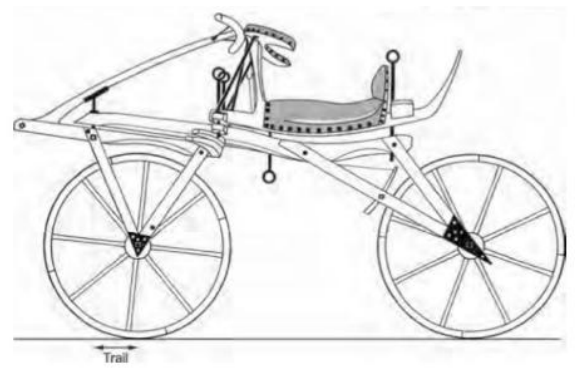

Figure 1: An adjustable draisine of 1817 [7] 


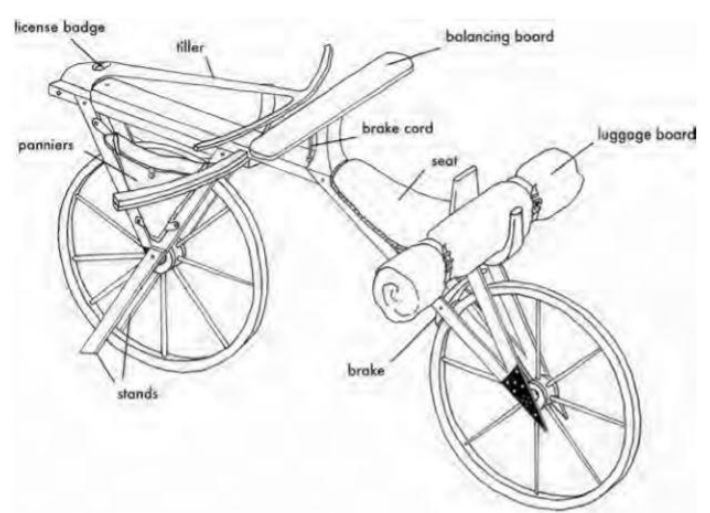

Figure 2: An isometric drawing of a draisine with options added [8]

\section{b) Era of 3 and 4-wheelers (1820s to 1850s)}

Even though this is technically not part of the (two-wheel) bicycle history, however during these decades, many developments have been made using the draisine as a basis. The draisine was just the start. Apparently three wheelers and four wheelers were expected to be more stable without too much increase in driving resistance [4]. Mechanics also came up with designs for a four-wheeler driven by a hand-cranked belt, pedals and levers as well as a three-wheeler with a high seat as shown in Figure 3[7]. These designs usually suffered from high weight and high rolling resistance. However, Willard Sawyer in Dover successfully manufactured a range of treadle-operated four wheel vehicles such as the vehicle shown in Figure 4 and exported them worldwide in the 1850s [9].

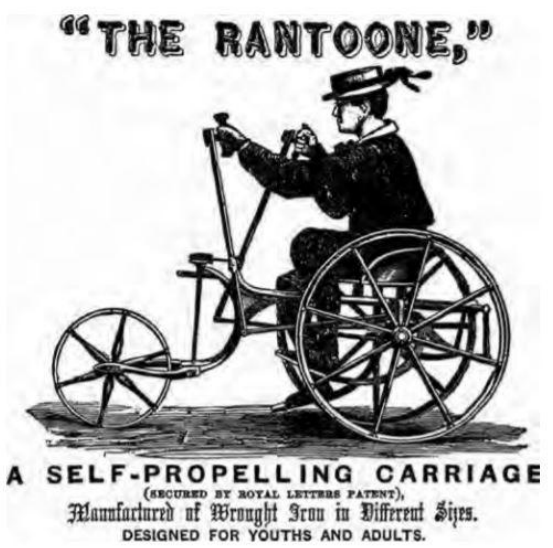

Figure 3: Advertisement pamphlet of the Rantoone[10].

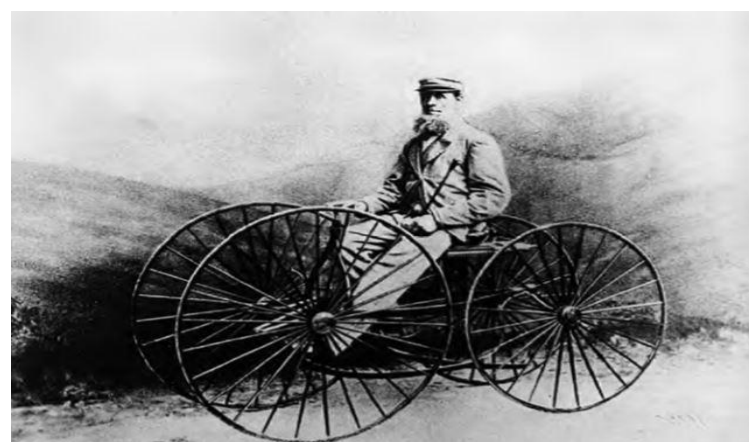

Figure 4: Willard Sawyer on his quadricycle, circa 1851 (Dover Museum). 


\section{c) Velocipedes and 'Bone Shaker' (1860s)}

The velocipede has always been further developed through various aspects such as adding lamp light, a change in velocipede design and many more. However, a milestone was reached when the first mechanically propelled two wheeled velocipede was designed. There had always been countless theories on its origin, but nevertheless, the first proven and patented design of a mechanically propelled velocipede during the year 1866 belongs to Pierre Lallement as shown in Figure 5 [11]. Lallement then sold his design to the Olivier Brothers whom in turn later formed partnership with the blacksmith, Pierre Michaux (1813 - 1883). Michaux's company which is also known as Michaux et Cie (Michaux and Company) had then started the industrial production of Lallement's bike design at 1868 [12]. In England, the velocipede earned the name of 'bone shaker' because of its rigid frame and iron branded wheels that gives the riders a bone shaking experience. The demand and supply of the velocipede then sky-rocketed as well as further improvements and research. Some of the various improvements which have been patented that came after the 'bone shaker' can be seen in Figure 6.

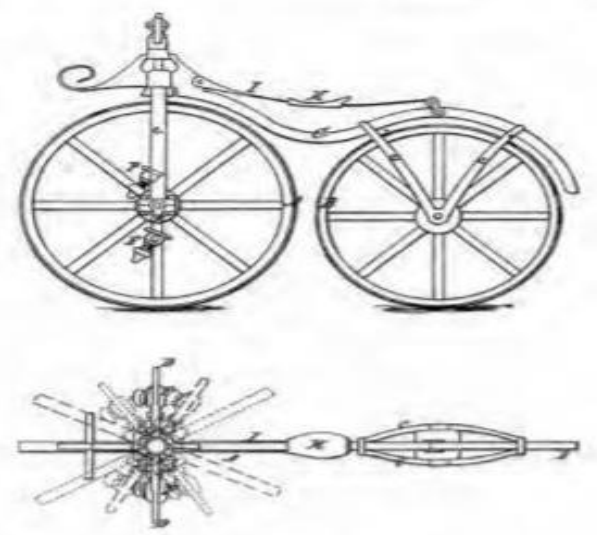

Figure 5: Pierre Lallement's US Patent No. 59,915 drawing, 1866 [11].

Based on Figure 6, the Hanlon Brothers first patented a very basic machine based on the first generation of Michaux Velocipede [13]. Dr. William Laubach provided a frame pivoted in the middle so the front wheels would not chafe the rider's legs [14]. Thomas Pickering introduced steam or gas tubing for the backbone and the wheel forks of an improved velocipede [15]. Joseph Irving provided a $45^{\circ}$ steering column that made it practicable to mount a front wheel with a diameter as large as 50 inches [16]. Lastly, William Racey obtained a patent for an original way to ease mounting, and make riding more social, by bolting two velocipedes together in parallel [17].
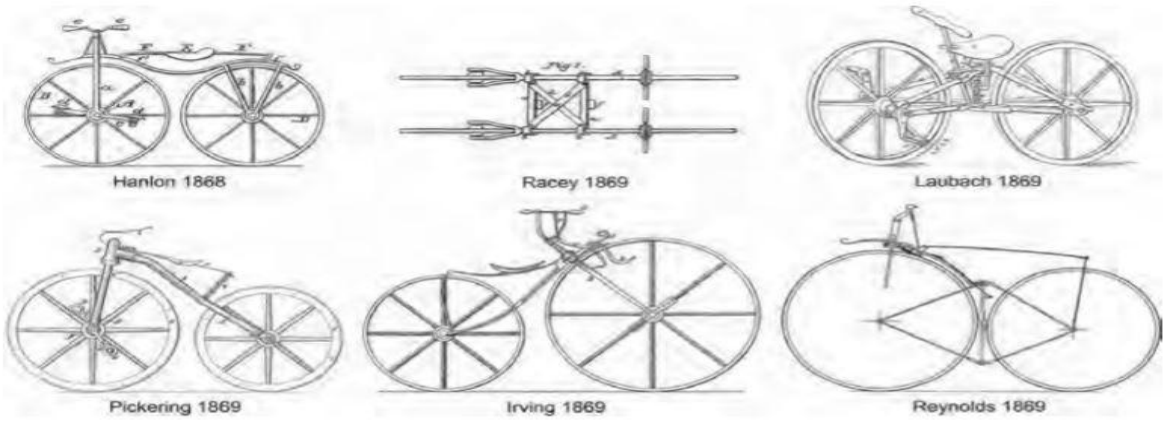

Figure 6: American and British patent drawings for velocipedes[13]-[17] 
d) High wheelers or ordinary bicycles @ Penny Farthing (1870s)

Larger wheels had less rolling resistance and this made it possible to achieve a higher speed with the optimal pedaling cadence [4]. This was how the evolution of 'bone shaker' to high wheelers initiated. The first man to build and publicise for industrial opportunities would be a Frenchman, Eugene Meyer [18]. The rear wheel was made smaller and the frame was built to be lighter and hollow. The wheels was enveloped with rubber solid and ball bearings were made used of. This evidently increases riding comfort as well [19]. Then, James Starley and William Hillman applied for a patent on "Improvements in the construction of wheels applicable chiefly to velocipedes, and in the driving gear for such vehicles" (British patent 2,236 of 1870) [4]. Starley then produced 'The Ariel' which was then commercialized due to its tangent wheel with tangent spokes as shown in Figure 7 [18]. The Ariel was a massive success. Using this as a momentum, Starley went on to become the most active wheel improver during the 1870s. The improvements of high wheelers continued in terms of stoking improvements, material substitution, and various mechanics including adding wheels and resulting to a high wheel tricycle [20]. Nevertheless, the dangers of the height limiting its top speed has always been an issue as well as balancing once turning is made in top speed.

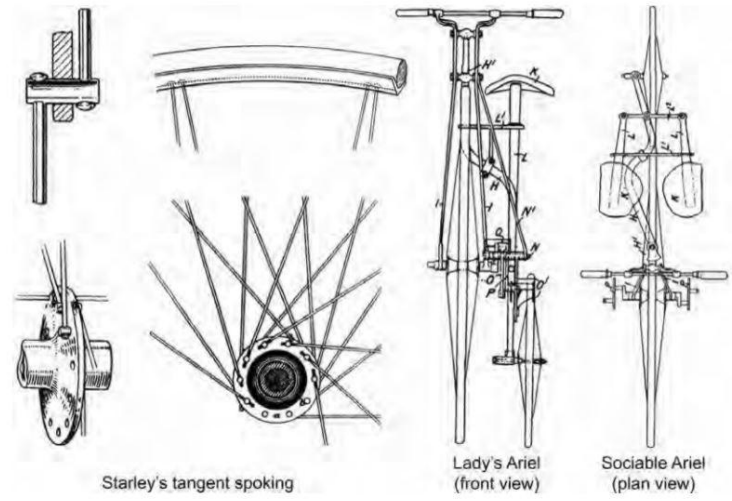

Figure 7: Starley's second spoke-wheel patent and bicycle designs for non-racers [18]

\section{e) Safety Bicycle (1880s - 1890s)}

It is obvious that a large wheel makes riding bicycle relatively difficult especially when travelling long distances. Hence, a primary drive system that allowed a smaller, more manageable driving wheel was therefore desirable [21]. Many types of technical advances occurred and various systems were tried, such as employing levers and cranks, belts and pulleys, rotary driveshaft, meshing spur wheels, and also chains and sprockets [4, p. 144]. However, the design that marked the most important turning point of the history of bicycle would be the unpatented design of John Kemp Starley's first successful 'safety bicycle' which was also known as 'rover' as shown in Figure 8 [22].

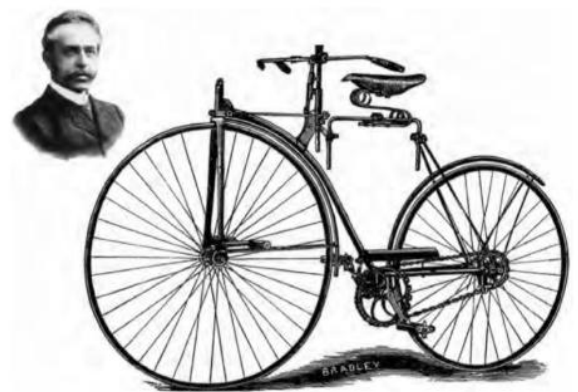

Figure 8: The first Starley Rover bicycle (1885) and an 1886 portrait of John Kemp Starley from a newspaper catalog[22]. 
The rover implemented all the high wheelers' and velocipedes' previous advancements. The size of the front wheel were significantly reduced. It has a balanced gear system with a rear wheel (non-steering wheel) chain drive making the handling much more proficient which will indirectly improve comfort and lets the rider to control speed more efficiently while maintaining safety [22]. The rover began to hit the global market at an astonishing rate. It could be seen that this design by far resembles a lot of the bicycle we see nowadays. This shows that the design advancements were no longer as obvious as to change every ten years like before the 19th century. The advancement or changes in bicycle design after this era of 'safety bicycle' began to be more specialized, such as comfort, transmission, tires, saddles, pedals, handlebars, lighting, luggage and frame designs for speed and the part which we would thoroughly review in this paper would be the braking system.

\subsection{Evolution of braking system}

The commonly used ideas behind all bicycle braking systems are to dissipate kinetic energy in the form of heat energy with the usage of friction. This commonly used idea evolved over time in terms of design and material composition resulting in different accomplishments.

\section{a) Tire brakes}

\section{i. Shoe, Spoon and Roller brakes}

The first bicycle, Drais's running machine, had a pivoting brake shoe that acted on the steel tire of the rear wheel whereby the rider applies the brake by pulling a cord under the armrest [4]. This type of braking system were also proposed by other inventors even until the 1890s, for example the Preston Helmon's US patent as shown in Figure 9 [23].

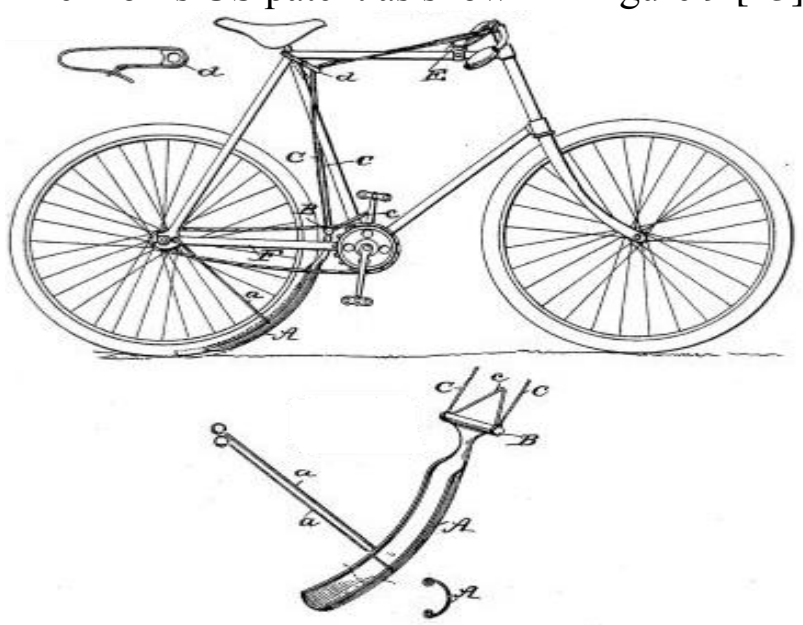

Figure 9: Helmon's skid shoe brake, shown here in a patent drawing, was like dropping a fender under the back wheel [23]

Then came the spoon and roller brakes. Spoon brakes are basically an evolved concave spoon-like shaped version of shoe brakes which fits the rounded tire section much better as it makes a fuller contact with the tire especially after the development of solid rubber tires with rounded cross sections [24]. The difference would only be the fact that shoe brakes were initially only curved in one plane only unlike spoon brakes [25]. Figure 10 shows an example of a simple, lightweight spoon brake of circa 1900, actuated by pulling a chain[25]. 


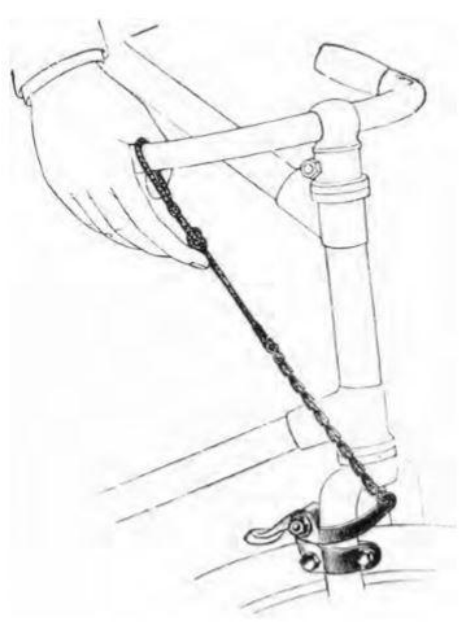

Figure 10: Spoon brake of circa 1900[25].

When the Michaux style velocipede made its appearance, so did roller brakes. Roller brakes are theoretically less damaging to the surface of the tire. When the expensive and fragile pneumatic tires came about, further development of roller brakes can be seen such as when Edward Rockwell of Connecticut patented an improved roller brake, with tapered rubber-tired rollers as shown in Figure 11[26]. Other American examples include Francis John Cole's 1894 design, with a single roller tapered at both ends [27]; William Stewart's roller brake of 1896, which had extended roller axles so that the rider could apply his feet to them for extra force [28]; and Abram Duck's 1897 design, which used two angled rubber rollers [29].

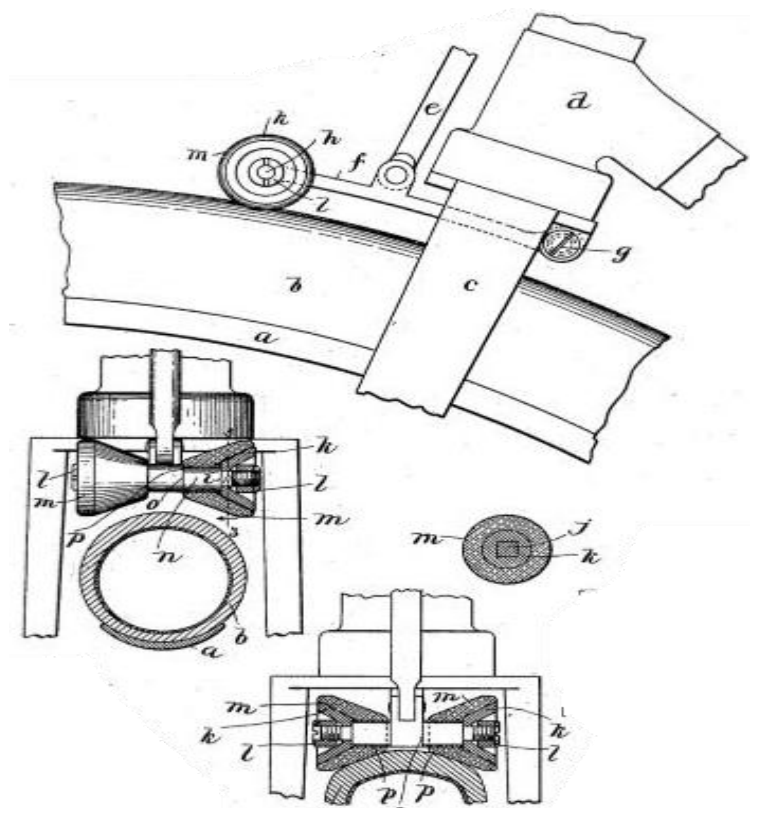

Figure 11: Edward Rockwell's patented improved roller brake design [26].

\section{ii. Pneumatic brakes}

In an 1893 design by the British engineer John George Kitchen, the rider compressed air by squeezing a rubber ball on the handlebar; the air then travelled through a thin rubber hose to a 
small inflatable brake block that, when inflated, acted on the top of the tire [30]. One perceived advantage of pneumatic brakes was the convenience of routing thin, flexible rubber hoses from the handlebar to the brake [4, p. 265]. Other inventors followed up on pneumatic brakes in many different ways such as shown in Figure 12 [31]\&Figure 13[32], however pneumatic brakes became just a passing fad as there were more reliable solutions to the linkage problem.

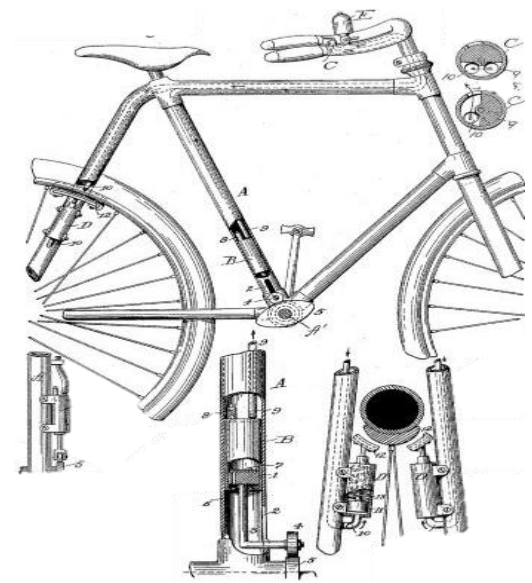

Figure 12: L. Bowles's patented pneumatic bicycle brake design [31]

\section{b) Rim Brakes}

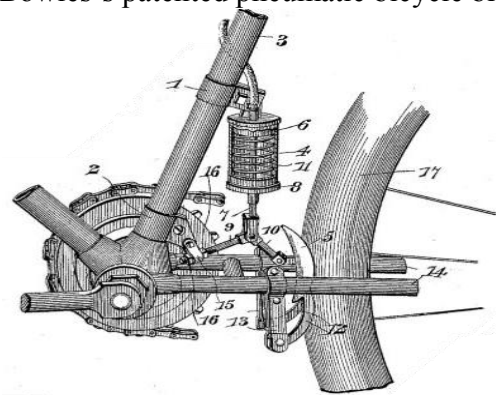

Figure 13: John H. Bowman's patented bicycle air brake design [32]

Rim brakes are brakes which exerts a braking force due to the friction force of the braking pad with the rim of the rotating wheel, thus slowing the bicycle.

\section{i. Roller-lever stirrup brakes}

Roller-lever stirrup brakes consists of thick metal rods and pivots to transmit the force that was applied to the hand lever to pull friction pads upwards instead of sideways against the inner surface, which faces the hub of the wheel rim as shown in Figure 14[25].

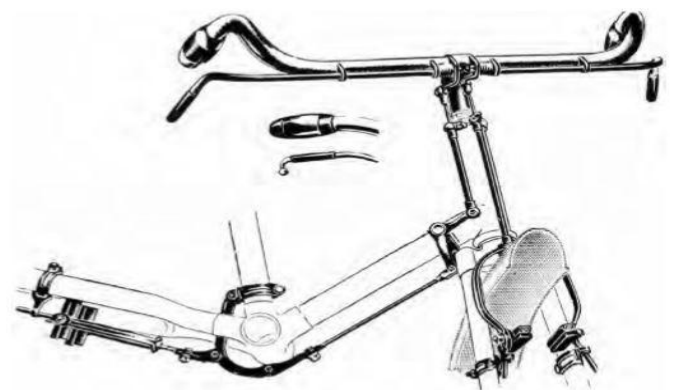

Figure 14: A classic roller-lever stirrup brake[25] 


\section{ii. Calliper Brakes}

Calliper brakes has a pair of pivoted brake arms that act on the sides of a wheel's rim using single or two pivots and can also be identified by either centre-pull or side-pull brake calliper [4, p. 269]. Calliper brakes works extremely well with Bowden cables which are particularly used for mechanical advantages. As the driver actuates force on the hand lever, the Bowden cable pulls the pivoted brake arms together, indirectly pulling the brake pads as well to the wheel's rim forcing it to come to a stop. The three common sub-types of calliper brakes can be seen in Figure 15-17[33]. The side pull bicycle brake calliper can either be of a single pivot type whereby the brake cantilever arms are pivoted through use of a brake cable about a single pivot point to apply brake pads against a bicycle rim, or a dual pivot type whereby a pair of dual pivoting points are utilized.The dual pivot moves the brake pads inwards and applies pressire on the tire which causes it to have more mechanical advantage compared to single pivoted side pull bicycle brake calliper [34].Lastly, a centre-pull brake calliper where each of its brake arms rotates around a pivot on each side of the wheel above the rim and both its brake shoes migrate upwards toward the wheel's rim to exert braking force [33].

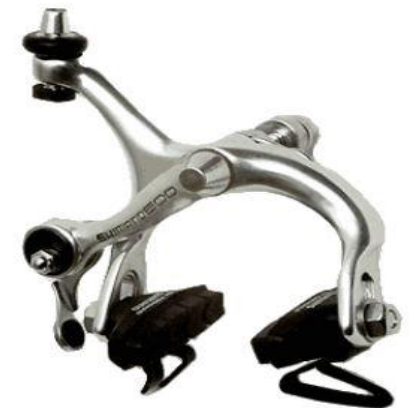

Figure 15: Single pivot Side-pull bicycle brake caliper [33]

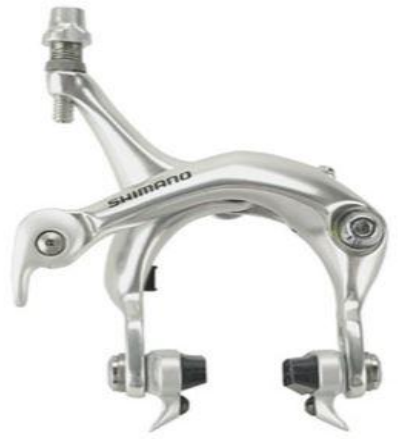

Figure 16: Dual pivot Side-pull bicycle brake caliper [33]

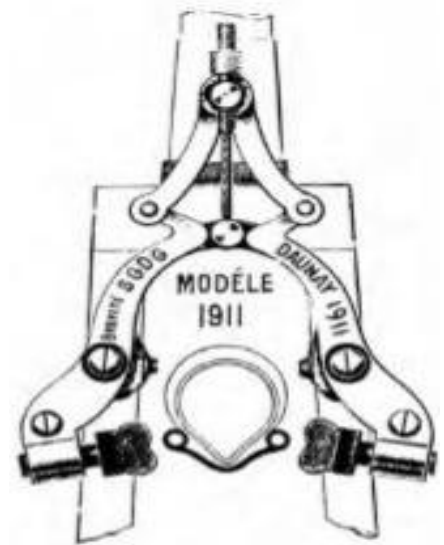

Figure 17: A 1911 Daunay Centre-pull Bicycle Brake Caliper[25] 


\section{iii. Cantilever brakes}

Caliper brakes are less effective as tires get wider therefore reducing the brakes' mechanical advantage, however traditional cantilever brakes have an outwardly-angled arm protruding on each side, a cable stop on the frame or fork to terminate the cable housing, and a straddle cable between the arms[35]. By applying the brakes or pulling the main line upwards, thereby pulling the middle of the transverse cable, the ends of the cantilever members, on which the transverse cables are anchored, cause inward pivotal movement of the brake shoes to touch the rim surface of the wheels[36]. An example of cantilever bicycle brake can be seen in Figure 18 [4, p. 277].

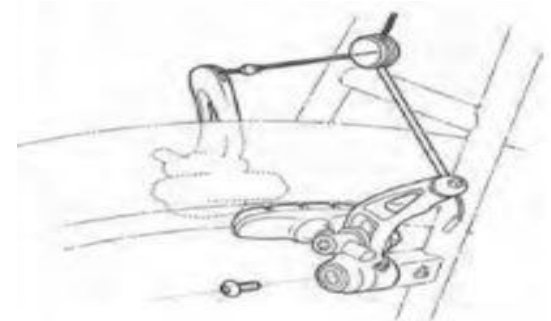

Figure 18: A cantilever brake of the sort used on mountain bikes in the 1980s (Geoff Apps).

\section{iv. Hydraulic rim brakes}

Hydraulic rim brakes are caliper type bicycle brakes which actuates simultaneously on the front and rear wheels due to a single actuator assembly mounted adjacent to the handlebar. As the brake handle is squeezed, hydraulic fluid under pressure is delivered to the brakes through two self-contained hydraulic circuits, one for the front brake and one for the rear brake[37]. An example of a patented hydraulic rim brake can be seen in Figure 19 [38]. The market for hydraulic rim brakes has been small but is growing. Their complexity, vulnerability, and cost are perceived to offset the advantages of almost lossless transmission of force between brake lever and brake block[39].

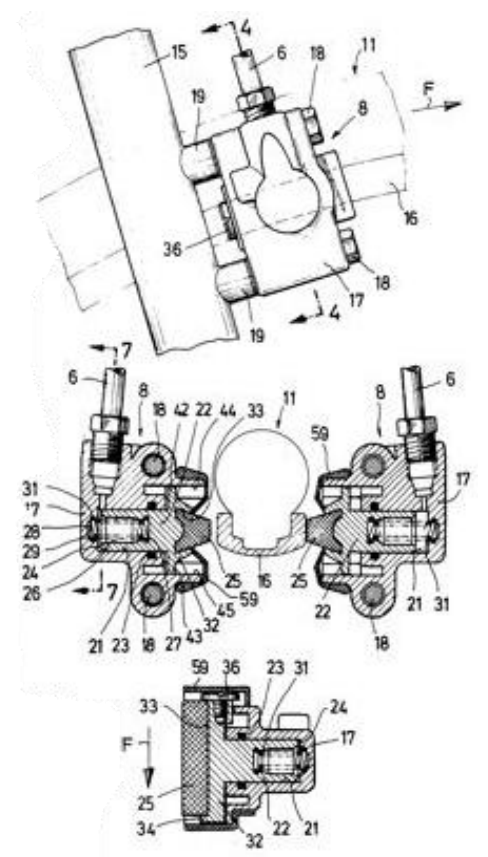

Figure 19: Gustav MagenwirthGmbh\& Co.'s hydraulic rim brake design[38] 


\section{C) Brakes in or attached to the hub}

\section{i. Coaster brakes}

Coaster brakes can be said to be the only braking system actuated by back-pedalling that had an enduring success. The usual operational characteristics of coaster brake is that forward rotation of the shaft (i.e., in a direction which causes the velocipede to travel forward) causes the wheel to rotate in the same direction; reverse rotation of the shaft operates the braking mechanism of the coaster brake assembly to retard the forward rotation of the wheel whereas in the absence of rotation of the shaft, the wheel rotates freely under its inertia independent of the shaft[40]. Attempts have been made to use a coaster brake in the rear hub but various difficulties have been experienced because of slack in the upper run of the chain particularly when the bicycle is being operated in one of the high speed positions[41]. These difficulties typically include failure of proper braking, disengagement of the chain from the sprockets with the resulting dangers therefrom[41].Coaster brakes are most commonly installed in the hub of the rear wheel of a bicycle which rotates about a fixed axle whereas another type of coaster brake is installed in the hub of the front wheel of tricycles or velocipedes, which is directly driven by a drive shaft on which the hub is mounted[40].Later, the coaster brakes with gear transmission which was patented by Seiji Fukui made debut in 1982. This kind of coaster brake hub comprises a non-rotatable shaft fixed to the bicycle frame, a hub shell, a driving member supported to the fixed shaft to be rotatable forwardly and reversely, a gear-transmission for transmitting the driving force from the driving member to the hub shell, and a braking mechanism for braking the hub shell by a reverse rotation of the driving member caused by back-pedaling[42]. An example of another variant of coaster brake design can be seen in Figure 20 [43].

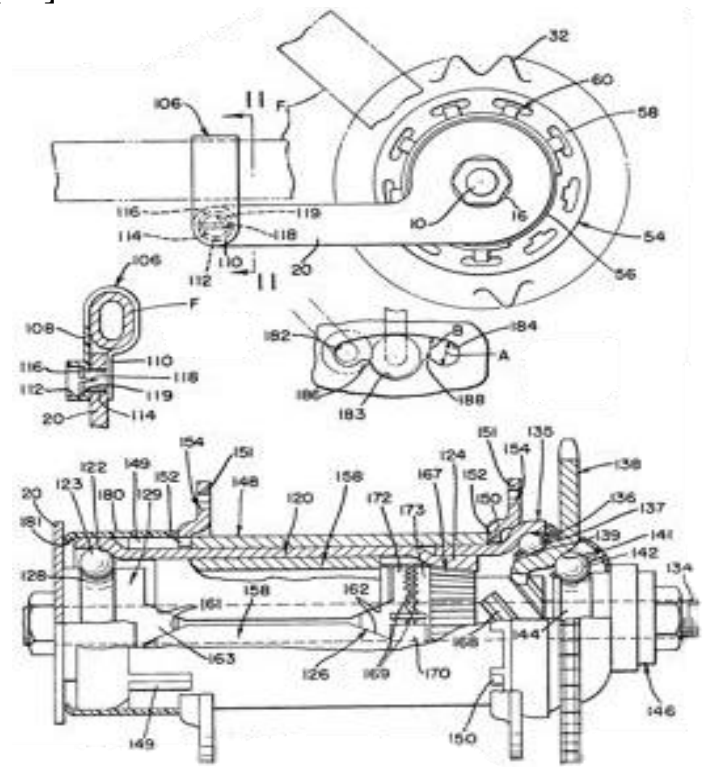

Figure 20: Patented coaster brake design of Baker Iii Elbert[43]

\section{ii. Internally Expanding Hand Operated Drum brakes}

A drum brake for bicycles includes a cylindrical hub having a flange at both sides and a circular recess at an end thereof, a screw rod extending through the hub and supported by a bearing arranged within the hub, brake means including a rotor and three brake blocks fitted on the screw rod and installed with the circular recess, a positioning plate provided with three guide rods adapted to be slid-ably engaged with respective hole of the brake blocks, an arm 
having a square opening receiving the square portion, a torsion spring bearing against the arm, and a cover fixedly mounted on the positioning plate, whereby the bicycle can be effectively reduced in speed or stopped in motion[44]. The prior art from the patent of I-Tai Lai and Feng Yuan gives a clear picture of drum brakes in general. Based on Figure 21 [44], the drum brake utilizes an arm to rotate a rectangular block to drive the pair of brake shoes to expand further causing friction between the brake shoes and the inner surface of the hub which will in turn reduce the speed or stopping the motion of the bicycle. Furthermore, in order for the brake shoes to return back to their original positions when the brake is released, two return springs are added to the design.

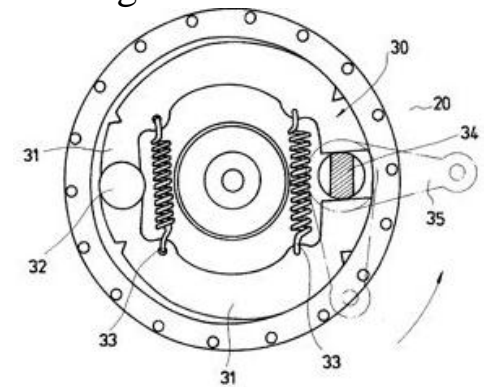

\section{iii. Disc brakes}

Figure 21: Prior art of I-Tai Lai \& Feng Yuan's Drum brake design[44]

Currently known disc brake apparatus can be mainly categorized, in terms of their actuation methods, into two systems of mechanical braking system and hydraulic braking system[45]. A disc brake for bicycles having a rotor mounted externally on a bicycle wheel hub and a brake housing mounted in a bracket affixed to the wheel axle wherein the brake housing has limited slidable movement in the support bracket to permit alignment with the rotor but is restrained from rotating about its own axis by a complementary opening and housing shape[46]. The brake includes a mechanically manipulated threaded actuator to apply brake motion with a high mechanical advantage[46].Due to the compliant mating of the coupling and compliant walls, the position of the linings can be adjusted conveniently and precisely[47]. One of the earliest bicycle disc brake design can be seen in Figure 22 [48].

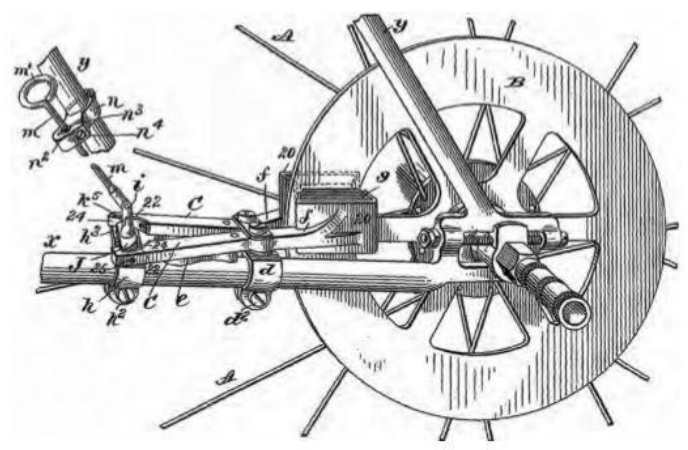

Figure 22: An 1894 design for a bicycle disc brake by Hendrick and Fay (patent drawing) [48]

Like other hub brakes, disc brakes are further away from other debris or mud when compared to the wheel rims as even the brake pads are retracted while remaining close to the disc itself, hence there is very little chance that any sort of debris would be trapped between the braking surfaces than there is between rim brakes [49]. Brake discs are harder than wheel rims, and disc brakes' pads are harder than rim brakes' blocks, so greater braking force can be used without the risk of excessive wear to the wheel rim[4, p. 289]. It is significantly easy to use 
disc brakes with very large tires and suspension. They also reduce the risk of instantaneous tire blow-outs caused by brake-wear-induced failure of the rim sidewalls or by overheating of the rims on long steep descents[4, p. 290].

The disc brakes has been received exceptionally well around the world. The business and developments has been blooming ever until now whereby many road racing bicycles utilizes disk brakes overlooking the added weight, cost and air resistance [50]. However, due to its extreme braking force, it has been more desirables for mountain bicycles instead as they were usually ridden on extremely steep roads or pathways. Unlike other rim brakes, disc brake exerts a considerable amount of torque at the hub like other hub brakes. A bicycle which is not designed to be fitted with disc brake may experience heavy stresses onto the spokes, rims and hub flanges. The weight of the tire may not be enough or a fork with insufficient size and strength may be used which may bring about a conventional front-wheel quick-release mechanism to work sufficiently loose from conventional dropouts to the point that the wheel comes out of the fork. Thus, it is very advisable that any bicycle made for use with disc brakes should have been designed with these factors in mind.

\section{Recent progress on Composite Materials used for braking applications on bicycles}

\subsection{Composite Materials}

A composite can be defined as a particular reinforcement such as natural, synthetic, metallic, organic or inorganic materials that is reinforced with a suitable matrix (i.e. polymers, metals, alloys, inorganic cements or glass) consisting of two or more phases [51, p. 16]. The said particular reinforcement has a phase that is usually discontinuous, stiffer, and stronger, whereas on the other hand, matrix is less stiff and its weaker phase is continuous [51, p. 16]. Due to chemical interactions and/or processing effects, an additional distinct phase known as interphase may co-exist between the reinforcement and matrix [52]. A simple illustration of a composite consisting of the three main components can be seen in Figure 23. The composite is designed so that the mechanical loads to which the structure is subjected in service are supported by the reinforcement whereas the function of the relatively weak matrix is to bond the fibers together and to transfer loads between them [53].The extent of interaction between the reinforcement and the matrix is a design variable, and it may vary from strong chemical bonding to weak frictional forces[54]. This can often be controlled by using an appropriate coating (interphase) on the reinforcing fibers[54].

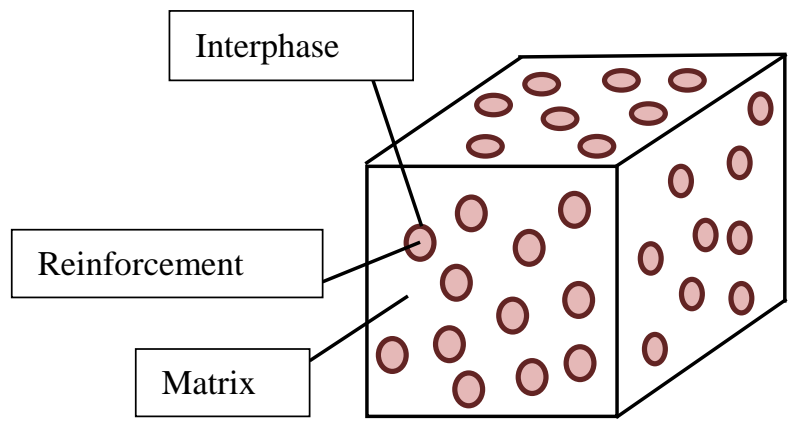

Figure 23: An illustration of a composite. 
The single most important parameter influencing the composite properties is the concentration of the composite material itself as it is used mainly to control and alter the properties of a composite [53]. Concentration of a composite material can be measured in terms of volume or weight fraction. The concentration of the composite material can be measured in mainly two aspects that are known as homogeneity and non-uniformity whereby homogeneity determines the extent to which a representative volume of material may differ in physical and mechanical properties from the average poperties of material whereas non-uniformity has always been avoided as it reduces the properties that governed the weakest link in the material [55].

\subsection{Polymer-Matrix Composite}

One of the most frequently used composite in making composite-based fabrications is the polymer-matrix composite (PMC). Polymer-matrix composites (PMCs) consist of a polymer resin as the matrix, with fibers as the reinforcement medium as shown in Figure 24 [56].

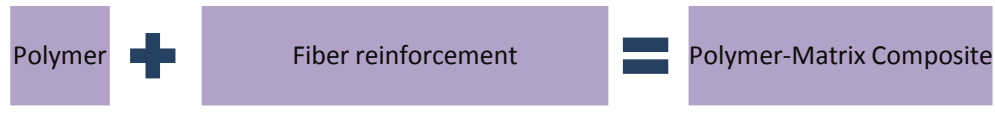

Figure 24: Components of Polymer-Matrix Composite [56]

Polymers can be defined as a naturally occurring or synthetic compound, such as starch or Perspex, which has large molecules made up of many relatively simple and repeated units. Polymers can be easily differentiated into three major categories known as:-

\section{a) Thermoplastics}

Thermoplastics are polymers that solidify as they are cooled, no longer allowing the long molecules to move freely, and when heated again, these materials regain the ability to "flow", as the molecules are able to slide past each other with ease[57].

\section{b) Thermosets}

Thermoset polymers solidify by a chemical curing process. Here, the long macromolecules crosslink with each other during curing, resulting in a network of molecules that cannot slide past each other[58]. The formation of these networks causes the material to lose the ability to "flow" even after reheating[57]. However a high cross linking density between the molecules makes thermosetting materials stiff and brittle[59].

\section{c) Elastomers}

Compared to thermosets, elastomers are only lightly cross linked, which permits almost full extension of the molecules[58]. However, the links across the molecules hinder them from sliding past each other, making even large deformations reversible[59]. Their ability to "flow" is lost after they are vulcanized or cross linked[57].

These polymers in each category have their own specialized usage and applications when used as a composite. Examples of the common polymers used in these three categories and their respective applications can be seen in Table 1. 


\begin{tabular}{|c|c|c|}
\hline Type of Polymer & Polymer & Applications \\
\hline \multirow{6}{*}{ Thermoplastics } & Polystyrene & $\begin{array}{l}\text { Mass-produced transparent articles, thermoformed packaging, foamed } \\
\text { packaging, and thermal insulation products, etc }\end{array}$ \\
\hline & Polymethyl methacrylate & $\begin{array}{l}\text { Skylights, airplane windows, lenses, bulletproof windows, automotive } \\
\text { stop lights, etc. }\end{array}$ \\
\hline & Polycarbonate & $\begin{array}{l}\text { Helmets, eyeglass lenses, CD's, hockey masks, bulletproof windows, } \\
\text { blinker lights, head lights, etc. }\end{array}$ \\
\hline & High density polyethylene & $\begin{array}{l}\text { Milk and soap bottles, mass production of household goods of higher } \\
\text { quality, tubes, paper coating, etc. }\end{array}$ \\
\hline & Polypropylene & $\begin{array}{l}\text { Goods such as suitcases, tubes, engineering application (fiber- } \\
\text { glass-reinforced), housings for electric appliances, etc. }\end{array}$ \\
\hline & Polyamide & $\begin{array}{l}\text { Bearings, gears, bolts, skate wheels, pipes, fishing line, textiles, ropes, } \\
\text { etc. }\end{array}$ \\
\hline \multirow{4}{*}{ Thermosets } & Epoxy & $\begin{array}{l}\text { Adhesive, glass fiber reinforced automotive leaf springs, carbon fiber } \\
\text { reinforced bicycle frames, aircraft wings and fuselage etc. }\end{array}$ \\
\hline & Melamine & $\begin{array}{l}\text { Decorative heat-resistant surfaces for kitchens and furniture, dishes, } \\
\text { etc. }\end{array}$ \\
\hline & Polyester & $\begin{array}{l}\text { Toaster sides, iron handles, satellite dishes, glass fiber reinforced } \\
\text { breaker switch housings and automotive body panels, etc. }\end{array}$ \\
\hline & Phenolics & Heat-resistant handles for pans, irons and toasters, electric outlets, etc \\
\hline \multirow[t]{4}{*}{ Elastomers } & Polybutadiene & $\begin{array}{l}\text { Automotive tires (blended with natural rubber and styrene butadiene } \\
\text { rubber), golf ball skin, etc. }\end{array}$ \\
\hline & Silicone rubber & $\begin{array}{l}\text { Seals, parts for medical applications, membranes, heat resistant } \\
\text { kitchen containers, etc. }\end{array}$ \\
\hline & $\begin{array}{l}\text { Natural rubber (polyiso- } \\
\text { prene) }\end{array}$ & Automotive tires, engine mounts, etc. \\
\hline & Ethylene propylene rubber & Automotive radiator hoses and window seals, roof covering, etc. \\
\hline
\end{tabular}

Table 1: Common Polymers and Some of Their Applications [57].

Table 1 clearly shows that most of the regularly used appliances in our everyday life especially in this 21 st century are made of polymers. Generally, these materials are used in the greatest diversity of composite applications, as well as in the largest quantities, in light of their room-temperature properties, ease of fabrication, and cost[54]. However its disadvantages lies in its low strength, low modulus and low operating temperatures which limits their usage [54].

Among the polymers mentioned, the most widely utilized and least expensive polymer resins are the polyesters and vinyl esters[60]. These matrix materials are usually utilized for glass fiber-reinforced composites. A large number of resin formulations provide a wide range of properties for these polymers. The epoxies are more expensive and, in addition to commercial applications, are also utilized extensively in PMCs for aerospace applications as they have better mechanical properties and resistance to moisture than the polyesters and vinyl resins[61].

\subsection{Polymer-Matrix Composite based on Natural Fibers}

The fiber reinforcement used in PMCs can be characterised into two categories; synthetic fiber and natural fiber. Figure 25 illustrates the characterization of fiber reinforcements used for polymer matrix composites as well as few examples [53].

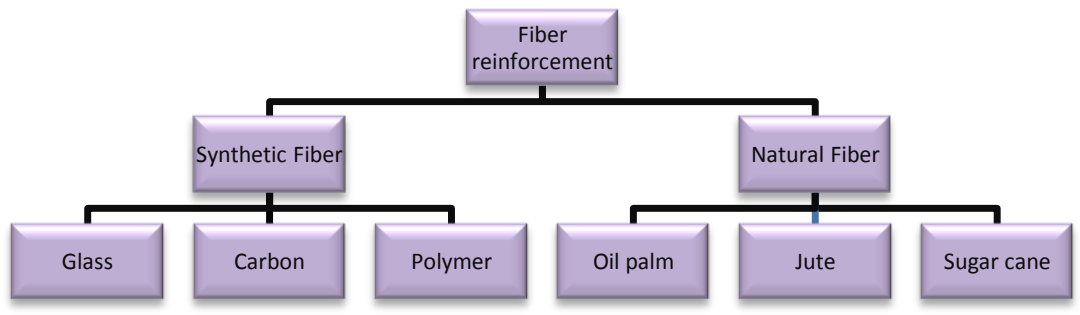

Figure 25: Characterization of Fiber reinforcement with examples[53]. 


\section{a) Synthetic Fiber}

The term 'synthetic' implies that synthetic fiber is a compound made artificially by chemical reactions. Synthetic fibers are man-made fibers and they are non-biodegradable as well as non-renewable [62]. Most synthetic fibers naturally outperform many natural fibers in terms of their strength and stiffness; however there are some natural fibers which are reported to be equally competitive to synthetic fibers. For instance, when natural fibers are treated with an adequate aqueous solution while taking into account the type of resin and catalyst used for composite fabrication, excellent mechanical and tribological properties can be achieved [63]. This fact opens the doorway for us to further research on natural fibers that can be used to replace the synthetic fibers which are being used in various industries. In the recent decades, a growing environmental awareness has been raised globally, many composite making industries have been shifting their interest into substituting synthetic fibers with natural fibers[64].

\section{b) Natural Fiber}

The word 'natural' implies that a specific substance is not man-made but formed naturally due to its surrounding environment whereas the word 'fiber' can be defined as a material composed of fine, elongated and threadlike filaments[65]. Natural fibres can be classified into three main categories: vegetable fibres (ex: cotton, flax, jute, banana), animal fibres (ex: silk, hair) and mineral fibres (ex: asbestos)[66].Natural fibres derived from plant-based fibres are preferred as reinforcements by the automotive industry for structural applications due to their high fibre strength properties[67]. Table 2 shows the natural fibre classification indicating types of plant and fibre groups.

\begin{tabular}{|c|c|c|c|c|c|}
\hline Wood fibre & Stalk fibre & Fruit fibre & Seed fibre & Leaf fibre & Bast fibre \\
\hline $\begin{array}{c}\text { Hardwood } \\
\text { Softwood } \\
\text { Sawdust }\end{array}$ & $\begin{array}{c}\text { Bamboo } \\
\text { Wheat } \\
\text { Rice } \\
\text { Grass } \\
\text { Barley } \\
\text { Corn }\end{array}$ & $\begin{array}{l}\text { Coconut } \\
\text { Betelnut }\end{array}$ & $\begin{array}{l}\text { Cotton } \\
\text { Alfalfa } \\
\text { Kapok }\end{array}$ & $\begin{array}{c}\text { Sisal } \\
\text { Manila } \\
\text { Banana } \\
\text { Palm } \\
\text { Mengkuang } \\
\text { Date palm } \\
\text { Pineapple } \\
\text { Abaca }\end{array}$ & $\begin{array}{c}\text { Rattan } \\
\text { Hemp } \\
\text { Jute } \\
\text { Ramic } \\
\text { Banana } \\
\text { Flax } \\
\text { Sugarcane } \\
\text { Kenaf } \\
\text { Roselle }\end{array}$ \\
\hline
\end{tabular}

Table 2: Types of plant and fibre groups [67]-[69].

As Malaysia is located near the equator, itshot and humid climate throughout the year makes Malaysia to be extremely suitable for planting cash-crops such as kenaf, oil palm, sugarcane, betelnut and coconut trees besides the usual timber. These cash-crops contains tremendous potential as renewable sources for alternative components or to be used as reinforcement for industrial products and applications, however this potential has not been fully exploited [53]. Using natural fibres is advantageous as it is more economical and is ecologically favourable [70]. The mechanical properties of some of these natural fibers compared to glass fibers can be seen in Table 3 .

\begin{tabular}{|c|c|c|c|c|c|c|c|}
\hline Type of fiber & $\begin{array}{l}\text { Density } \\
\left(\mathrm{g} / \mathrm{cm}^{3}\right)\end{array}$ & Elongation (\%) & $\begin{array}{c}\text { Tensile } \\
\text { strength } \\
\text { (Mpa) } \\
\end{array}$ & $\begin{array}{l}\text { Young's Mod- } \\
\text { ulus (Gpa) }\end{array}$ & $\begin{array}{l}\text { Specific } \\
\text { gravity }\end{array}$ & $\begin{array}{l}\text { Specific Mod- } \\
\text { ulus (GPa) }\end{array}$ & Ref. \\
\hline Cotton & 1.5-1.6 & $2.1-12.0$ & $200-600$ & "5.0-15.1 & 1.5 & $3.3-10.1$ & [71] \\
\hline Flax & $1.3-1.5$ & $1.1-3.3$ & $340-1600$ & $25.0-81.0$ & 1.5 & $16.7-54.0$ & $\begin{array}{l}71], \\
{[72]}\end{array}$ \\
\hline Ramie & $1.4-1.5$ & $1.5-4.0$ & $200-1000$ & $41.0-130.0$ & $1.5-1.6$ & $27.3-81.0$ & $\begin{array}{l}\text { [71], } \\
{[72]}\end{array}$ \\
\hline Bamboo & $1.2-1.5$ & $1.9-3.2$ & $500-575$ & $27.0-40.0$ & $0.4-0.8$ & $67.9-50.0$ & [73] \\
\hline Hemp & 1.1-1.6 & $0.8-3.0$ & $285-1735$ & $14.4-44.0$ & 1.5 & $9.6-29.3$ & [72], \\
\hline
\end{tabular}




\begin{tabular}{|c|c|c|c|c|c|c|c|}
\hline & & & & & & & [74] \\
\hline Oil Palm & $0.7-1.6$ & $4.0-18.0$ & $50-400$ & $0.6-9.0$ & $1.1-1.2$ & $0.5-7.5$ & $\begin{array}{l}\text { [77], } \\
{[78]}\end{array}$ \\
\hline Betel nut & $0.2-0.4$ & $22.0-24.0$ & $120-166$ & $1.3-2.6$ & $1.3-1.4$ & $1.0-1.9$ & [79] \\
\hline $\begin{array}{l}\text { Sugarcane Bio- } \\
\text { gases }\end{array}$ & $1.1-1.6$ & $6.3-7.9$ & $170-350$ & $5.1-6.2$ & $1.4-1.5$ & $3.6-4.1$ & $\begin{array}{l}{[80],} \\
{[81]}\end{array}$ \\
\hline Pineapple & 1.56 & 2.4 & $150-1627$ & $11.0-82.0$ & $1.4-1.6$ & $7.8-57.0$ & [84] \\
\hline E-glass & 2.5 & $2.5-3.0$ & $2000-3500$ & 70.0 & 2.6 & 26.9 & $\begin{array}{l}711, \\
{[76]}\end{array}$ \\
\hline S-glass & 2.5 & 2.8 & 4570 & 86 & $2.0-2.5$ & 34.4 & $\begin{array}{l}\text { [71], } \\
{[76]}\end{array}$ \\
\hline
\end{tabular}

Table 3: Mechanical properties of natural fibres and synthetic glass fibres [53]

*(Remark: ND - Not Determined)

Based on Table 3, it can be noticed that the tensile strength of glass fibres is relatively higher than that of natural fibres, however considering the specific modulus of natural fibres, it can be seen that natural fibres show values that are comparable to or better than those of glass fibres. The natural fibers as reinforcement in polymeric composites has a major advantage when it comes to specific properties as theirs are much higher when compared to glass fibers. This plays a crucial role especially when the desired properties in a composite focuses onto weight reduction. When it comes to automobile or any transport machinery, lightweight properties are highly valued and this makes natural fibers the best alternative to look at when it comes to developing or improving the performance of a particular part in those said automobile.

\subsection{Current progress of composite materials usage on bicycle}

Composites materials have been in usage in almost all industries, hence there is no surprise in the usage of composite materials for bicycle especially since one of its main aspects prioritised is speed. The need of speed spells the need of weight reduction when it comes to materials used to make the bicycle itself. One of the most famous composite material which has been booming in the automotive industry is none other than the carbon fibercomposite. In most cases, the bicycle enthusiast have found that a multi-layer carbon fiber wheel that utilizes different types of appropriately oriented carbon fiber materials tends to form the best and most structurally strong frames [85].It has very excellent strength relative to its light weight making it the most wanted material when it comes to a specification upgrade of a vehicle and this also includes bicycle. However, carbon fiber can be considered to be expensive, which is why when a part of a bicycle is designed, the design is applicable to many types of composite with different matrix and reinforcement combinations which brings in the potential of discovery of a type of composite which may possibly bring about comparative results with affordable prices instead due to abundance of resources [86]. Every company has their very own secret manufacturing recipe and are always having their research and development team to research different types of materials. Besides, there are too many bicycle products in the market with diversified materials as an ingredient that it makes it difficult to get a rough picture of exactly what composite are being made use most frequently to the point it dominates the market. However, some of the general matrix and general reinforcements which are currently being used in the industry are as shown in Table 4. 


\begin{tabular}{c|c|c|c}
\hline Bicycle part & Matrix & Reinforcement Material & Aspects that are focused upon \\
\hline \hline Frame & & Carbon fiber & Weight reduction \\
Handlebar & Glass fiber & Compressive strength \\
Tire & Boron fiber & Tensile strength \\
Wheel rim & Wood fiber & Tribological capabilities \\
Disk brake & thermoset plastic matrix & Ceramic fiber & Heat resistant \\
Brake calliper & & Metal coated fiber & \\
Brake pad & & Aramid & \\
\hline
\end{tabular}

Table 4: General matrix and reinforcement used to fabricate bicycle parts currently in the industry [85]-[93].

\subsection{Fabrication methods for natural fiber composites}

There have been various diversified methods when it comes to fabricating composite based components. Most general methods have been borrowed (ex: injection molding, poltrusion), however numerous methods were developed particularly by specialised companies or industries to meet specific design or manufacturing challenges. The selection of a fabrication method highly depends on the material used, part design as well as end use or application [94]. Some of the mostly used fabrication method are as follows:-

\section{a) Wet hand lay-up method}

Hand lay-up method can be said to be the most simple fabrication method. As it could be seen in Figure 26, wet hand lay-up molding is the method of laying down reinforced fiber mats onto another reinforced fibre mat that had already been painted with matrix resin with light pressure as to remove any trapped air painted with matrix resin to later also be painted with matrix resin layer by layer in order to achieve the preferred thickness over a mold. After the desired thickness has been achieved, the mold would then be closed and astatic applied load or pressure would be applied onto the closed mold as a curing process. A release film should already be placed initially onto the mold before placing the reinforced fiber mats in the first place for easy removal of the mold from the end product. A non-reinforced polymer layer, often called a "gel coat" might also be put at the mold side of the part after placing the release film as this creates a smooth surface that may be more attractive than the fiber-containing material[95]. The gel coat might contain a decorative film, such as the logo for a ski or skateboard manufacturer. The advantages and disadvantages of wet hand lay-up fabrication method can be seen in Table 5 .

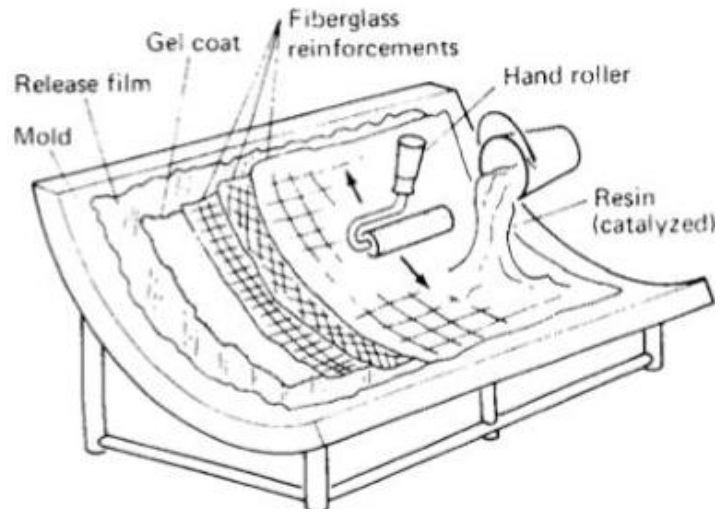

Figure 26: Wet hand lay-up process [95]. 


\begin{tabular}{l||l}
\hline & Design flexibility \\
& Large and complex items can be produced \\
& Production rate requirements are low \\
& Minimum equipment investment is necessary \\
& Tooling cost is low \\
Advantages & Any material that will hold its shape can be used as a mold form \\
& The start-up lead time and cost are minimal \\
& Design changes are easily affected \\
& Molded-in inserts and structural reinforcements are possible \\
& Sandwich constructions are possible \\
& Semi-skilled workers are needed, and are easily trained \\
\hline & The process is labor-intensive \\
& Only one good (molded) surface is obtained \\
& Quality is related to the skill of the operator \\
& It is a low-volume process \\
& Longer cure times required \\
& The waste factor is high \\
\hline
\end{tabular}

Table 5: Advantages and disadvantages of wet hand lay-up fabrication method.

\section{b) Wet Spray up method}

Wet spray-up method is basically an extension from the hand lay-up method. The reinforcement fiber are chopped to desired length (usually one inch) and are mixed into the resin with its catalyst. This mixture is then delivered continuously to a nozzle that can be hand-held or moved by suitable machinery in order to be sprayed onto the already set up mold with the release film as well as the gel coat, giving a short-fiber composite with random fiber orientation. The entire process can be seen in Figure 27 whereas the advantages and disadvantages of the fabrication method are as shown in Table 6.

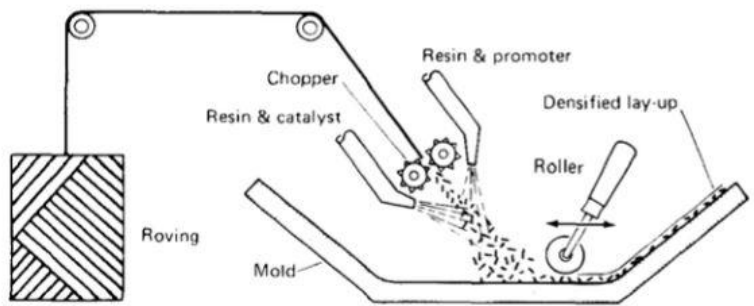

Figure 27: Wet spray-up process [95]

\begin{tabular}{l|l}
\hline \multirow{2}{*}{ Advantages } & $\begin{array}{l}\text { Can be altered and designed to be automated } \\
\text { Variable production capabilities } \\
\text { Low cost in relative to processing time of applying resin and fiber }\end{array}$ \\
\hline \multirow{3}{*}{ Disadvantages } & $\begin{array}{l}\text { Only short fibres can be incorporated } \\
\text { Resins need to be low in viscosity to be spray-able } \\
\text { Airborne styrene concentrations are limited to legislated levels }\end{array}$ \\
\hline
\end{tabular}

Table 6: Advantages and disadvantages of wet spray-up fabrication method.

\section{c) Resin Transfer Molding (RTM)}

The most promising fabrication method of natural fiber composites currently used by industries arethe resin infusion processes that are based on resin transfer molding (RTM), vacuum-assisted RTM (VARTM) and a number of process variations on these two basic infusion methods. The RTM is a process with a rigid closed mold. Figure 28 summarizes the main steps for a simple RTM process. The laminated reinforced fiber must first be soaked in resin and placed upon each other layer over layer and this is basically known as preform. The mold is then closed and the preform would be compacted. Soon after, the resin would be injected into the mold using a positive gradient pressure through the gate points replacing the 
air trapped within the preform. Usually, vacuum would be used at the dedicated vents in order to let the air escape from the mold. Once the resin reaches the vents, the gates would be clamped and the preform would then be impregnated. This would then be the starting point of the curing phase. Finally the mold would then be opened and the parts would be removed. For aerospace structures, an additional free-mold post-curing phase can be necessary in order to thoroughly guarantee the polymerization of the matrix and release the internal thermal stress[96]. The advantages and disadvantages of resin transfer molding are as shown in Table 7.

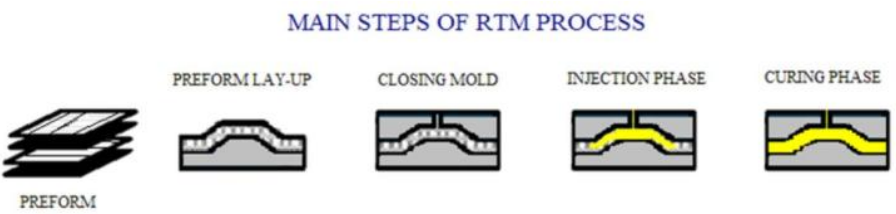

Figure 28: Sequence of the main steps of RTM process. From left to right: realization of the preform, deposition and draping of the preform in the mold cavity, closing mold, injection phase and curing phase; after the curing phase, the mold is opened and manufactured element is demolded[96]

\begin{tabular}{l|l}
\hline & Good surface finish on both sides \\
& Selective reinforcement and accurate fiber management achievable \\
& Ability to build in fiber volume fraction loading up to 65\% \\
& Uniformity of thickness and fiber loading, uniform shrinkage \\
& Inserts may be incorporated into moldings \\
& Tooling costs comparatively low \\
& Uses only low pressure injection \\
& Low volatile emission during processing \\
& Ability to produce near net shape moldings \\
& Process can be automated, resulting in higher production rates \\
& Ability to mold complex structural and hollow shapes \\
& Low resultant voids \\
\hline \multirow{3}{*}{ Disadvantages } & Waste some material (spill) \\
& Long period for curing \\
& Hard for intricate parts \\
\hline
\end{tabular}

Table 7: Advantages and disadvantages of resin transfer molding

\section{Summary of Review works}

Based on the review works done on bicycle brakes and their evolutions especially in their material composition aspect from year 1817, a few important points can be highlighted which are as listed below:

- The first two wheeled vehicle in existence known as Draisinewhich was manually propelled using legs was created by Baron Karl Drais at 1817.

- Due to balancing difficulties, three-wheelers and four-wheelers (with draisine as the basis) took the market but these soon led to the development of hand cranked belts, pedals and levers.

- The first proven and patented design of a mechanically propelled velocipede during the year 1866 belongs to Pierre Lallement. This velocipede earned the name of 'Boneshaker' because of its rigid frame and iron branded wheels that gives the riders a bone shaking experience.

- Larger wheels had less rolling resistance and this makes it possible to achieve a higher speed with the optimal pedalling cadence. James Starley produced 'The Ariel' which was then commercialized especially due to its available tangent wheel with tangent spokes. The improvements of high wheelers continued in terms of stoking improvements, material substitution, and various mechanics. 
- A primary drive system that allowed a smaller, more manageable driving wheel was therefore desirable resulting in the evolution to John Kemp Starley's first unpatented safety bicycle design. Safety bicycle has a balanced gear system with a rear wheel (non-steering wheel) chain drive making the handling much more proficient which will indirectly improve comfort and let the rider to better grasp speed while maintaining safety.

- Braking system of bicycles has its own evolution as well from tire brakes to rim brakes to brakes in or attached to the hub.

- The two possible ways to improve the braking system would either be the design or the material used.

- Materials used to fabricate bicycles are focusing more on composites as they have special characteristics.

- The global researches have been moving towards substituting synthetic composites with natural composites as much as possible due to environmental benefits.

- Natural composites have proven its possibilities of achieving favorable results in terms of mechanical properties as well as lightweight aspect further proving its capabilities of substituting synthetic composites of its the current usage used in bicycles.

- The Vacuum assisted resin transfer molding method of fabrication would result in the highest fiber to resin ratio when compared to hand layup as well as spray up method.

To the best of author's knowledge and from past review works, it can be summarized that evolution of bicycle braking system would bring about immense benefits and is vital to mankind as it plays a heavy role for safety. However, the idea of incorporating natural fiber in the development of bicycle braking system has not been widely implemented in the industry. As this is still a blooming aspect to be researched as well as there are an abundance of natural fibers in Malaysia which can be properly made use of, it would only be proper to incorporate a particular natural fiber into the bicycle braking system to see if a favorable result can be achieved.

\section{Future Research Pathways on Braking System used in Bicycles}

Based on the review works done on bicycle brakes and their evolutions especially in their material composition aspect from year 1817, we can still see that the technology of braking applications in bicycle can be further improved opening new research pathways. As such, certain areas worthy of exploration may include (but are not limited to) the following:

- What other different natural fiber composites can be used to fabricate the brake caliper which may bring about a more optimum result prioritizing strength, lightweight as well as heat dissipating capabilities?

- Can there be advancements in weather-proofing capabilities when natural fiber composites are used to fabricate the brake components of the bicycle?

- Can therebe a much better breakthrough design concept which may bring about better results in terms of exerting braking force while being lightweight just like when disc brakes were first introduced?

Future research in these areas would bring about a massive alteration in the materials used in the bicycle industry as well as better performance when it comes to the bicycles themselves. In addition, the findings from these explorations may also thoroughly affect other transport braking systems and are not only tied down to bicycles. 


\section{References}

[1] K. Sudesh and T. Iwata, "Sustainability of Biobased and Biodegradable Plastics," CLEAN - Soil, Air, Water, vol. 36, no. 5-6, pp. 433-442, 2008.

[2] V. C. EVR Almeida, Elisabete Frollini, Alain Castellan, "No Title," Carbohydr. Polym., vol. 80, no. 3, pp. 655-664.

[3]D. N. Saheb, J. P. Jog, D. Nabi Saheb, and J. P. Jog, "Natural Fiber Polymer Composites : A Review," Adv. Polym. Technol., vol. 18, no. 4, pp. 351-363, 1999.

[4]T. Hadland and H.-E. Lessing, Bicycle Design: An Illustrated History. The MIT Press Cambridge, Massachusetts London, England, 2014

[5]H.E.Lessing, How sophisticated was the draisine? The Boneshaker. 2002.

[6]C. Hoefer, "A Short Illustrated History of the Bicycle," www.crazyguyonabike.com, 2007. .

[7]H.-E. Lessing, "Automobilität_Karl Drais und die unglaublichen Anfänge.," in Maxime, .

[8]H.-E. Lessing, "The origin of the two-wheeler. A solution for the climatic crisis of 1816.," in Cycle History, 2012.

[9]D. Herlihy, Bicycle: The History. Yale University Press, 2004.

[10]A. Light Dragoon, Wheels and Woes. Words of Warning to Would be Velocipedists. London: Ward \& Lock, 1870 .

[11]A. G. Mokeb, “Improvement in velocipedes,” USRE7972 E, 1877.

[12]G. J. Malppan and T. Sunny, “A Review on Design Developments in Bicycle,” Int. Res. J. Eng. Technol., pp. 2395-56, 2015.

[13]The Hanlon Brothers, “Development in velocipedes," US 79,654, 1968.

[14]W. Laubach, "Improvement in velocipedes," 86,235, 1869.

[15]T. Pickering, "Improved velocipede," US 88507, 1869.

[16]J. Irving, "Improvement in velocipedes," US 89149, 1869.

[17]W. Racey, "Improvement in velocipede," US 90,302, 1869.

[18]H. W. Bartleet, "Spokes," in The Motorcyclist, 1928.

[19]A. Gardellin, History of the velocipede bike sport. 1941.

[20]H. Sturmey, “Weymouth: High-wheeler," in Sturmey’s Indispensable Bicyclist's Handbook, 1879.

[21]G. Norcliffe, The Ride to Modernity: The Bicycle in Canada, 1869-1900 - Glen Norcliffe - Google Books. University of Toronto Press, 2001.

[22]J. Tarring, "Rover Bicycle," CTC Monthly Gazette, 1885.

[23]P. Helmon, "Bicycle Brake," 583371, 1897.

[24]R. Redfield, "Bike braking vibration modelling and measurement," Procedia Eng., vol. 72, pp. 471-476, 2014.

[25]Noguchi-san, "The Data Book," in 100 Years of Bicycle Component and Accessory Design, San Francisco: Van der Plas: Illustrations, 2002.

[26]Edward D. Rockwell, "Brake for bicycle wheels," US524839, 1894.

[27]Francis John Cole, "Bicycle Brake," US540637, 1895.

[28]WIlliam L. Stewart, “Bicycle Brake,” US576912, 1897.

[29]Abram W. Duck, “Bicycle Brake," US594234, 1897.

[30]A. Sharp, "Bicycle \& Tricycles," in An Elementary Treatise on Their Design and Construction, Longmans,., London: MIT Press, 1896, p. 528.

[31]Lewis Bowles, “Pneumatic Bicycle Brake,” US597456, 1898.

[32]John H. Bowman, "Bicycle Air Brake,” US610796, 1898.

[33]S. Brown and J. Allen, "Installing and Adjusting Calliper Brakes," 2008. [Online]. Available: http://www.sheldonbrown.com/calipers.html.

[34]Barry J. Viola, “Center pull bicycle brake assembly," US5626209A, 06-May-1997.

[35]John McIntyre, "Brake assembly for a bicycle," US 20140291078 A1, 2013.

[36]Daniel Towle, "Cantilever brake device," US 8127896 B2, 2009.

[37]Lynn A. Williams, George P. Costello, and Leonard R. Malkowski, "Hydraulic bicycle brake system,” US 3993174 A, 1976.

[38]Ludwig Rottenkolber and Manfred Schwab, “Hydraulic rim brake for bicycles,” US 4585094 A, 1986.

[39]R. Lloyd-Jones and M. J. Lewis, Raleigh and the British Bicycle Industry: An Economic and Business History, 1870--1960. Taylor \& Francis, 2017.

[40]Brent E. Reed, “Coaster brake assembly,” US5027930 A, 1991. 
[41]J Anthamatten, "Coaster brake system for a multi-speed bicycle,” US3785219A, 05-Jun-1972.

[42]Seiji Fukui, "Coaster brake hub with a gear-transmission," US4323146 A, 1980.

[43]Baker Iii Elbert H, "Bicycle coaster brake," US3170549 A, 1961.

[44]I-Tai Lai and Feng Yuan, "Structure of a drum brake for bicycles," US5673773 A, 1996.

[45]Szu-Fang Tsai, "Bicycle disc brake apparatus,” EP2789871 B1, 2013.

[46]Karl Frei and Edwin Elliott Hood, "Bicycle disc brake," US3675741 A, 1971.

[47]Ah-Ping Lin, "Bicycle disk brake device," US7007776 B1, 2005.

[48]And Arthur H. Fay, "Brake for velocipedes," US526317 A, 1893.

[49]H. Lü, W. Bin Shangguan, and D. Yu, "A unified approach for squeal instability analysis of disc brakes with two types of random-fuzzy uncertainties,” Mech. Syst. Signal Process., vol. 93, pp. 281-298, 2017.

[50]E. Lindberg, N. E. Hörlin, and P. Göransson, “An experimental study of interior vehicle roughness noise from disc brake systems,” Appl. Acoust., vol. 74, no. 3, pp. 396-406, 2013.

[51]U. Nirmal, "Betelnut Fibers as Bio-reinforcements in Polyester Composites for Mechanical and Tribological Applications," Multimedia University, 2011.

[52]M.A de Farias, M.Z. Farina, A.P.T. Pezzin, and D.A.K. Silva, "Unsaturated polyester composites reinforced with fiber and powder of peach palm: Mechanical characterization and water absorption profile," Mater. Sci. Eng. C, vol. 29, no. 2, pp. 510-513, Mar. 2009.

[53]U. Nirmal, J. Hashim, and M. M. H. Megat Ahmad, "A review on tribological performance of natural fibre polymeric composites,” Tribol. Int., vol. 83, pp. 77-104, 2015.

[54]Princeton, "Polymer Matrix Composites," in Advanced Materials by Design, 1988, p. 73.

[55]U. Nirmal, N. Singh, J. Hashim, S. T. W. Lau, and N. Jamil, "On the effect of different polymer matrix and fibre treatment on single fibre pullout test using betelnut fibres," Mater. Des., vol. 32, no. 5, pp. 2717-2726, 2011.

[56]B. D. Agarwal and L. J. Broutman, Analysis and Performance of Fiber Composites, 2nd Editio. New York: WILEY-VCH Verlag, 1990.

[57]G. M. Tim A. Osswald, "Polymers," in Material Science of Polymers for Engineers, 2010.

[58]A. Calhoun and A. Peacock, "Properties and Applications," in Polymer Chemistry, Hanser Publishers, Ed. Munich: Hanser Publishers, 2006.

[59]L. (Editor) Hollaway, Handbook of Polymer Composites for Engineers. Lancaster, PA: Technomic Publishing Company, 1994.

[60]D. Hull and T. W. Clyne, An Introduction to Composite Materials, 2nd editio. New York: Cambridge University Press, 1996.

[61]W. D. Callister, “Composites,” Mater. Sci. Eng. An Introd. 7th Ed., pp. 577-620, 2006.

[62]F. FournouA, Synthetic fibers : machines and equipment, manufacture , properties: handbook for plant engineering, machine design, and operation. Hanser/Gardner Publications, 1999.

[63]U. Nirmal, "Synthetic Fibers," Betelnut Fibers as Bio-reinforcements Polyest. Compos. Mech. Tribol. Appl., 2011.

[64]B. F. Yousif, "Evaluation of Natural and Synthetic Fibers: Reinforced Polyester Composites subjected to Adhesive and Abresive Wear," 2010.

[65]A. L. Kernerman, “Dictionary News,” pp. 3-5, 2014.

[66]U. Riedel and J. Nickel, "Applications of Natural Fiber Composites for Constructive Parts in Aerospace, Automobiles, and Other Areas," in Biopolymers Online, A. Steinbüchel, Ed. Weinheim, Germany: Wiley-VCH Verlag GmbH \& Co. KGaA, 2005.

[67]J. Holbery and D. Houston, "Natural-fiber-reinforced polymer composites in automotive applications," JOM, vol. 58, no. 11 , pp. 80-86, Nov. 2006.

[68]U. Nirmal, J. Hashim, S. T. Lau, Y. My, and B. Yousif, "Betelnut fibres as an alternative to glass fibres to reinforce thermoset composites: A comparative study,” Text. Res. J., vol. 82, no. 11, pp. 1107-1120, Jul. 2012.

[69]Z.N. Azwa, B.F. Yousif, A.C. Manalo, and W. Karunasena, "A review on the degradability of polymeric composites based on natural fibres," Mater. Des., vol. 47, pp. 424-442, May 2013.

[70]T. H. Nam, S. Ogihara, N. H. Tung, and S. Kobayashi, "Effect of alkali treatment on interfacial and mechanical properties of coir fiber reinforced poly(butylene succinate) biodegradable composites," Compos. Part B Eng., vol. 42, no. 6, pp. 1648-1656, Sep. 2011.

[71]A. Bledzki and J. Gassan, “Composites reinforced with cellulose based fibres,” Prog. Polym. Sci., vol. 24, no. 2, pp. 221-274, May 1999.

[72]T. Sen and H. Reddy, "Various industrial applications of hemp, kinaf, flax and ramie natural fibres," vol. 2, no. 3, pp. 8-192, 2011. 
[73]H.P.S.Abdul Khalil, I.U.H.Bhat, M.Jawaid, A.Zaidon, D.Hermawan, and Y.S.Hadi, "Bamboo fibre reinforced biocomposites: A review," Mater. Des., vol. 42, pp. 353-368, Dec. 2012.

[74]L.Marrot, A.Bourmaud, P.Bono, and C.Baley, "Multi-scale study of the adhesion between flax fibers and biobased thermoset matrices," Mater. Des., vol. 62, pp. 47-56, Oct. 2014.

[75]S. Narish, B. F. Yousif, and D. Rilling, "Adhesive Wear of Thermoplastic Composite Based on Kenaf Fibres,” Proc. Inst. Mech. Eng. Part J J. Eng. Tribol., vol. 225, no. 2, pp. 101-109, Feb. 2011.

[76]B. Vijaya Ramnath, V. M. Manickavasagam, C. Elanchezhian, C. Vinodh Krishna, S. Karthik, and K. Saravanan, "Determination of mechanical properties of intra-layer abaca-jute-glass fiber reinforced composite," Mater. Des., vol. 60, no. August, pp. 643-652, 2014.

[77]S. Shinoj, R. Visvanathan, S. Panigrahi, and M. Kochubabu, "Oil palm fiber (OPF) and its composites: A review," Ind. Crops Prod., vol. 33, no. 1, pp. 7-22, Jan. 2011.

[78]K. G. Berger, "Production of palm oil from fruit," J. Am. Oil Chem. Soc., vol. 60, no. 2, pp. 206-210, Feb. 1983.

[79]B. Rashid, Z. Leman, M. Jawaid, M. J. Ghazali, and M. R. Ishak, "Physicochemical and thermal properties of lignocellulosic fiber from sugar palm fibers: effect of treatment," Cellulose, vol. 23, no. 5, pp. 2905-2916, 2016.

[80]M. K. Hossain et al., "Comparative mechanical and thermal study of chemically treated and untreated single sugarcane fiber bundle," Ind. Crops Prod., vol. 58, pp. 78-90, Jul. 2014.

[81]J. M. Paturao, "Alternative Uses of Sugarcane and its byproducts in Agroindustries." [Online]. Available: http://www.fao.org/docrep/003/s8850e/S8850E03.htm. [Accessed: 01-Oct-2017].

[82]K. Bilba, M. Arsene, and A. Ouensanga, "Study of banana and coconut fibersBotanical composition, thermal degradation and textural observations," Bioresour. Technol., vol. 98, no. 1, pp. 58-68, Jan. 2007.

[83]J. L. Guimarães, E. Frollini, C. G. da Silva, F. Wypych, and K. G. Satyanarayana, "Characterization of banana, sugarcane bagasse and sponge gourd fibers of Brazil," Ind. Crops Prod., vol. 30, no. 3, pp. 407-415, Nov. 2009.

[84]N. Kengkhetkit and T. Amornsakchai, "Utilisation of pineapple leaf waste for plastic reinforcement: 1. A novel extraction method for short pineapple leaf fiber," Ind. Crops Prod., vol. 40, pp. 55-61, Nov. 2012.

[85]Andrew Ording and Joshua R. Poertner, "Composite bicycle rim with seamless braking surface," US6991298 B2, 27-Nov-2002.

[86]Kent S. Whiting and Kevin B. Hulick, "Composite handlebar for bicycles," WO2003044421 A2, 2002.

[87]Martin Danzer, Gregor Stuehler, and Harald Moser, "Bicycle disk brake," CA2621893 A1, 2008.

[88]曾宝城 “Composite material bicycle rim structure,” CN201784401 U, 2010.

[89]张建 沈永清, and 袁永全, “Carbon fiber composition material bicycle disk brake hook claw strengthening structure," CN101962060 A, 2009.

[90]James Colegrove and David Guzik, "Light weight and high performance braking composite clincher or tubular tire bicycle wheel rim," WO2004074081 A3, 2004.

[91]Giuseppe Dal Pra, "Rim for a bicycle wheel made from composite material with a wear indicator and wheel comprising such a rim," US7918514 B2, 2008.

[92]Paolo Fabris, "Bicycle wheel component with braking area made of composite material and related manufacturing process," US20170100960 A1, 2016.

[93]James Colegrove and David Guzik, "Light weight and high performance braking composite bicycle wheel rim," WO2004074010 A2, 2004.

[94]B.-H. Lee, H.-J. Kim, and W.-R. Yu, "Fabrication of long and discontinuous natural fiber reinforced polypropylene biocomposites and their mechanical properties," Fibers Polym., vol. 10, no. 1, pp. 83-90, Feb. 2009.

[95]C. Wittman and G. D. Shook, "Hand Lay-Up Techniques," in Lubin G. (eds) Handbook of Composites, Boston, MA: Springer US, 1982, pp. 321-367.

[96]C. Sumanta Bhandary and B. Sanyal, Composites and Their Properties. InTech, 2012. 